\title{
Evaluation of hearing in children with familial Mediterranean fever: A study during attack and attack-free periods
}

\author{
Claudio Andaloro', Veronica Castro², Ignazio La Mantia² \\ 'Ear Nose and Throat Unit, Santa Marta e Santa Venera Hospital, Acireale, Catania, Italy \\ 2Department of Medical Sciences, Surgical and Advanced Technologies, GF Ingrassia, University of Catania, Italy
}

\section{ABSTRACT}

Introduction: Few studies have investigated the hearing in familial Mediterranean fever (FMF), with conflicting results reported. The aim of this study was to compare the cochlear functions of FMF children with healthy controls and to evaluate any differences in the audiological outcomes of FMF patients during attack and attack-free periods.

Material and methods: In this study were recruited 50 FMF children and 31 healthy children as controls. FMF patients that were in an attack period and a control group underwent audiometric evaluation including pure tone audiometry and Distortion Product Otoacoustic Emission (DPOAE) test. The evaluation was repeated in FMF patients in an attack-free period. Additionally, auditory brainstem response (ABR) test was performed during attack and attack-free periods.

Results: Hearing thresholds of FMF patients, compared to the control group, were found to be increased at all frequencies on the left and at 1000,4000 , and $8000 \mathrm{~Hz}$ on the right $(p<0.05)$. This was supported by the DPOAE test, with lower values at all frequencies in FMF children $(p<0.05)$. In the attack period, compared to the attack-free period, hearing thresholds were found to be increased only at certain frequencies, but this was not supported by the DPOAE test $(p>0.05)$. No statistically significant difference between attack and attack-free period for ABR test were found (all $p>0.05$ ).

Conclusions: Our results demonstrated cochlear involvement in FMF patients, but no objective acute impairment in hearing in the attack period, which suggests that hearing impairment in FMF is due to chronic autoinflammation process.

KEY WORDS:

familial Mediterranean fever, cochlear function, hearing, distortion product otoacoustic emission, audiometry.

\section{INTRODUCTION}

Familial Mediterranean fever (FMF) is a hereditary autosomal recessive autoinflammatory disorder that is common among people of the Mediterranean basin, including Jewish, Arabian, Turkish, and Armenian populations [1].
In Italy it was long considered a very rare disease, in spite of its Mediterranean location, but now several papers reported Italian cases of FMF [2,3], especially in central-southern areas [4]. Symptoms of FMF comprise recurrent fever with abdominal pain, pleurisy, arthritis, and skin lesions [5]. The symptomatic period is termed as "at-

\section{ADDRESS FOR CORRESPONDENCE:}

Claudio Andaloro, Ear, Nose, and Throat Unit, Santa Marta e Santa Venera Hospital, Via Caronia, 95024,

Acireale, Catania, Italy, e-mail: cla.anda@gmail.com 
tack". The patients have no symptoms during the intervals between attacks, which is an important feature for diagnosis [6]. The gene associated with the disease (MEFV gene Chr 16p13.3) was first identified in 1997 by two groups [7, 8 ] and encodes a 781-aminoacid protein (pyrin/marenostrin) involved in the regulation of inflammation and apoptosis [9]. FMF usually starts in childhood; in a multicentre study in which both adults and children were involved, the average initial age of diagnosis of the disease was $9.6 \pm 8.6$ and $16.4 \pm 11.6$ years, respectively [10].

Among associated diseases or manifestations, FMF is seen particularly together with Henoch-Schönlein purpura and polyarteritis nodosa [11]. The frequent association of amyloidosis and vasculitis with FMF suggests that these clinical conditions influencing many organs can also affect hearing [12].

There are a limited number of studies about the effects of familial Mediterranean fever on auditory functions. The majority of these studies were conducted in adults [13], often with controversial findings. In some of these studies, FMF patients, when compared to the healthy group, showed elevated hearing thresholds and decreased otoacoustic emission, supporting cochlear involvement $[12,14]$, whereas other studies report no significant difference between these two groups $[6,15]$.

In this study, we aimed to compare the cochlear functions of FMF children with healthy controls and to evaluate any differences in the audiological outcomes of FMF patients during the attack and attack-free periods, by using distortion product otoacoustic emission (DPOAE) test, pure tone audiometry $(250-8000 \mathrm{~Hz})$, and auditory brainstem response (ABR) test.

\section{MATERIAL AND METHODS}

This case-control, three-group interventional study was performed at the Otorhinolaryngology Unit, Santa Marta e Santa Venera Hospital, Acireale, Catania, Italy, from 2014 to 2017. A total of 50 children diagnosed with FMF according to Tell-Hashomer criteria [16] were referred to our clinic for further evaluation from the Paediatric Clinics of the same hospital, and 31 healthy children were included in the study as a control group. The study protocol was approved by the Ethics Committee of Unità Operativa Complessa di Otorinolaringoiatria-ASP 3 CT, P.O. Acireale, Italy and conducted in accordance with the ethical principles described in the Declaration of Helsinki. Written, informed consent was obtained from all parents and children.

The children with active ear infections, acute otitis media, otitis media with effusion, chronic otitis media, and otitis externa, those with a positive history of ototoxic agent use, and those not eligible for hearing tests were excluded. The patients and the control group were evaluated with a detailed ear, nose, and throat (ENT) examination with audiological evaluation including tympanometry, audiometry, and DPOAE tests for both ears. In addition, 11 patients were also tested for ABR. All these evaluations were done in both attack and attack-free periods. Primarily, the tympanometry was performed using a GSI 37 tympanometer (Grason-Stadler Inc., Eden Prairie, Minnesota, USA) to prove that middle ear function was normal.

Tonal audiometry was performed in a totally isolated cabin with the AC-40 audiometer (Interacoustics, Middelfart, Denmark) and TDH-39P headphones (Interacoustics A/S, Denmark). Air-conduction and bone-conduction thresholds were measured at frequencies of $250-8000 \mathrm{~Hz}$ intervals. Pure-tone average (PTA) was used to determine the hearing loss. A hearing level of $<25 \mathrm{~dB}$ was considered normal in the tested frequencies.

Measurements of distortion product otoacoustic emissions (DPOAEs) were carried out for all subjects while the subjects were seated in a soundproof test room with portable equipment used in hearing screening programs (AccuScreen, Madsen - Otometrics, Denmark). Once the probe was placed with a good seal in the ear canal, the measurements were done. Two pure-tone stimuli at $65 / 50 \mathrm{~dB}$ SPL $(\mathrm{f} 2: \mathrm{f} 1=1.22$ ) were presented to the ear simultaneously and DPOAEs were measured at five different frequencies ranging from 1000 to $4000 \mathrm{~Hz}$ (1000, 1400, 2000, 2800, and $4000 \mathrm{~Hz}$ ).

ABR test was performed on each FMF patient during an attack period, and it was repeated in an attack-free period with an automated ABR (GSI AUDIOscreener+; Grason-Stadler, Minneapolis, MN) after sedation with oral or intramuscular sedatives. Analysis time was 10 seconds. One electrode was placed on each earlobe and a third on the forehead for grounding. Electrode impedance was less than $5000 \mathrm{Ohms}$ and inter-electrode impedance was within $2000 \mathrm{Ohms}$. Click stimuli were set to an 80 decibel hearing level ( $\mathrm{dB}$ HL). The click was averaged across 1000 sweeps and was replicated. Waves I, III, and $\mathrm{V}$ were identified and their latencies were recorded. Wave I and wave $\mathrm{V}$ amplitudes were determined for $80 \mathrm{~dB} \mathrm{HL}$ click-evoked waveforms. ABR was detected by placing electrodes on the scalp and separating the response from background electroencephalography measures using averaging and amplification techniques [17].

Although the absolute latencies can be influenced by peripheral hearing loss, the inter-peak latencies are generally accepted as measures of central neural conduction time and are influenced by myelination of nerve fibres [18]. All audiometric evaluations were performed at the same centre by the same audiologist.

\section{STATISTICAL ANALYSIS}

All statistical analyses were performed using SPSS software version 20.0 (SPSS Inc., Chicago, IL, USA). Descriptive statistics were expressed as mean $\pm S D$ (standard deviation) and number. Kolmogorov-Smirnov test was used to evaluate the distribution of variables. 
Independent sample $t$-test was used for continuous variables with normal distribution, and Mann-Whitney $U$-test was used for continuous variables without normal distribution. Significance was accepted at $p<0.05$ for all statistical analyses.

\section{RESULTS}

The mean age was $12.1 \pm 3.9$ years in the FMF group and $11.3 \pm 3.5$ years in the control group. There were 24 boys and 26 girls in FMF group, and 15 boys and 16 girls in the control group. There were no significant differences between the patient and the control group with respect to age and gender distribution $(p>0.05)$.

The hearing thresholds were analysed separately for the right and the left ear in all study groups and are shown in Table 1. There were statistically significant higher hearing levels in FMF patients, when compared to the control group, at all frequencies (250 to $8000 \mathrm{~Hz}$ ) and pure tone average (PTA) on the left and at 1000, 4000, $8000 \mathrm{~Hz}$ and PTA on the right $(p<0.05)$.
Also, a significant difference was found in terms of DPOAEs between both groups $(p<0.05)$ with lower values in FMF children compared to the control group at all frequencies (1000 to $4000 \mathrm{~Hz})(p<0.05)$ except for $1000 \mathrm{~Hz}$ on the right ear $(p>0.05)$ (Table 2$)$.

When we compared the results of the audiological survey performed in the attack period with those in the attack-free period, we found significant differences for the hearing levels in the audiogram only at frequencies of 250,1000 , and $8000 \mathrm{~Hz}$ and pure tone average on the left and $1000 \mathrm{~Hz}$ and pure tone average on the right $(p<0.05)$. Moreover, this difference was not supported by the DPOAE test (all $p>0.05$ ).

Additionally, there was no statistically significant difference between attack and attack-free period for ABR wave latencies and inter-peak intervals (all $p>0.05$ ) (Table 3).

\section{DISCUSSION}

There are few published studies conducted on patients at paediatric age attempting to elucidate the direct rela-

TABLE 1. Comparison of the audiometry values between the three groups for both ears

\begin{tabular}{|c|c|c|c|c|c|c|c|c|c|}
\hline \multirow{2}{*}{$\begin{array}{l}\text { Audiometric } \\
\text { frequency }(\mathrm{Hz})\end{array}$} & \multirow[t]{2}{*}{ Groups } & \multirow{2}{*}{$\begin{array}{l}\text { Left } \\
\text { hearing } \\
\text { levels mean } \\
\pm S D\end{array}$} & \multicolumn{3}{|c|}{$p$ values } & \multirow{2}{*}{$\begin{array}{l}\text { Right } \\
\text { hearing } \\
\text { levels mean } \\
\pm S D\end{array}$} & \multicolumn{3}{|c|}{$p$ values } \\
\hline & & & $\begin{array}{c}\text { FMF A } \\
\text { vs. control }\end{array}$ & $\begin{array}{c}\text { FMF A-F } \\
\text { vs. } \\
\text { control }\end{array}$ & $\begin{array}{c}\text { FMF A } \\
\text { vs. FMF } \\
\text { A-F }\end{array}$ & & $\begin{array}{l}\text { FMF A vs. } \\
\text { control }\end{array}$ & $\begin{array}{c}\text { FMF A-F } \\
\text { vs. } \\
\text { control }\end{array}$ & $\begin{array}{c}\text { FMF A } \\
\text { vs. } \\
\text { FMF A-F }\end{array}$ \\
\hline \multirow[t]{3}{*}{250} & FMF A & $12.53 \pm 3.29$ & \multirow[t]{3}{*}{0.002} & \multirow[t]{3}{*}{0.043} & \multirow[t]{3}{*}{0.039} & $9.66 \pm 2.17$ & \multirow[t]{3}{*}{0.287} & \multirow[t]{3}{*}{0.288} & \multirow[t]{3}{*}{0.768} \\
\hline & FMF A-F & $9.66 \pm 2.34$ & & & & $9.52 \pm 2.01$ & & & \\
\hline & Control & $7.13 \pm 1.96$ & & & & $8.29 \pm 1.98$ & & & \\
\hline \multirow[t]{3}{*}{500} & FMF A & $9.52 \pm 2.51$ & \multirow[t]{3}{*}{0.026} & \multirow[t]{3}{*}{0.029} & \multirow[t]{3}{*}{0.774} & $9.88 \pm 3.95$ & \multirow[t]{3}{*}{0.316} & \multirow[t]{3}{*}{0.353} & \multirow[t]{3}{*}{0.341} \\
\hline & FMF A-F & $9.83 \pm 2.48$ & & & & $8.42 \pm 2.34$ & & & \\
\hline & Control & $6.37 \pm 1.78$ & & & & $7.53 \pm 1.53$ & & & \\
\hline \multirow[t]{3}{*}{1000} & FMF A & $11.48 \pm 3.06$ & \multirow{3}{*}{0.003} & \multirow{3}{*}{0.045} & \multirow{3}{*}{0.048} & $10.92 \pm 2.05$ & \multirow[t]{3}{*}{0.013} & \multirow[t]{3}{*}{0.044} & \multirow[t]{3}{*}{0.047} \\
\hline & FMF A-F & $8.92 \pm 2.63$ & & & & $8.97 \pm 1.85$ & & & \\
\hline & Control & $6.62 \pm 1.46$ & & & & $6.15 \pm 1.93$ & & & \\
\hline \multirow[t]{3}{*}{2000} & FMF A & $9.46 \pm 3.26$ & \multirow[t]{3}{*}{0.006} & \multirow[t]{3}{*}{0.002} & \multirow[t]{3}{*}{0.654} & $7.84 \pm 2.07$ & \multirow[t]{3}{*}{0.307} & \multirow[t]{3}{*}{0.256} & 0.556 \\
\hline & FMF A-F & $10.19 \pm 3.54$ & & & & $8.28 \pm 2.65$ & & & \\
\hline & Control & $5.28 \pm 1.44$ & & & & $6.68 \pm 1.21$ & & & \\
\hline 4000 & FMF A & $9.54 \pm 2.67$ & 0.005 & 0.006 & 0.664 & $9.77 \pm 2.58$ & 0.006 & 0.007 & 0.788 \\
\hline & FMF A-F & $9.88 \pm 2.23$ & & & & $9.24 \pm 2.43$ & & & \\
\hline & Control & $4.47 \pm 1.55$ & & & & $3.92 \pm 1.76$ & & & \\
\hline 8000 & FMF A & $11.25 \pm 2.29$ & 0.004 & 0.042 & 0.046 & $9.14 \pm 2.31$ & 0.043 & 0.047 & 0.872 \\
\hline & FMF A-F & $8.67 \pm 2.33$ & & & & $9.09 \pm 1.97$ & & & \\
\hline & Control & $6.61 \pm 1.79$ & & & & $6.35 \pm 1.39$ & & & \\
\hline PTA & FMF A & $12.12 \pm 2.15$ & 0.007 & 0.041 & 0.039 & $13.23 \pm 2.37$ & 0.006 & 0.042 & 0.037 \\
\hline & FMF A-F & $10.68 \pm 2.38$ & & & & $10.26 \pm 2.21$ & & & \\
\hline & Control & $7.21 \pm 2.15$ & & & & $7.88 \pm 2.10$ & & & \\
\hline
\end{tabular}

FMFA - familial Mediterranean fever attack period, FMF A-F - familial Mediterranean fever attack-free period, SD - standard deviation, PTA - pure tone average 
TABLE 2. Comparison of the DPOAE values between the three groups for both ears

\begin{tabular}{|c|c|c|c|c|c|c|c|c|c|}
\hline \multirow[t]{2}{*}{ DPOAEs (Hz) } & \multirow[t]{2}{*}{ Groups } & \multirow{2}{*}{$\begin{array}{c}\text { Left } \\
\text { DPOAE } \\
\text { mean } \pm S D\end{array}$} & \multicolumn{3}{|c|}{$p$ values } & \multirow{2}{*}{$\begin{array}{c}\text { Right } \\
\text { DPOAE } \\
\text { mean } \pm S D\end{array}$} & \multicolumn{3}{|c|}{$p$ values } \\
\hline & & & $\begin{array}{c}\text { FMF A } \\
\text { vs. control }\end{array}$ & $\begin{array}{c}\text { FMF A-F } \\
\text { vs. control }\end{array}$ & $\begin{array}{c}\text { FMF A } \\
\text { vs. FMF A-F }\end{array}$ & & \begin{tabular}{|c|} 
FMF A \\
vs. control
\end{tabular} & \begin{tabular}{|c|} 
FMF A-F \\
vs. control
\end{tabular} & $\begin{array}{c}\text { FMF A } \\
\text { vs. FMF A-F }\end{array}$ \\
\hline \multirow[t]{3}{*}{1000} & FMF A & $5.53 \pm 5.19$ & \multirow[t]{3}{*}{0.027} & \multirow[t]{3}{*}{0.033} & \multirow[t]{3}{*}{0.412} & $6.58 \pm 4.01$ & \multirow[t]{3}{*}{0.089} & \multirow[t]{3}{*}{0.083} & \multirow[t]{3}{*}{0.682} \\
\hline & FMF A-F & $6.06 \pm 4.46$ & & & & $6.32 \pm 3.97$ & & & \\
\hline & Control & $9.46 \pm 6.08$ & & & & $8.65 \pm 5.42$ & & & \\
\hline \multirow[t]{3}{*}{1400} & FMF A & $6.43 \pm 4.87$ & \multirow[t]{3}{*}{0.021} & \multirow[t]{3}{*}{0.020} & \multirow[t]{3}{*}{0.912} & $6.29 \pm 4.97$ & \multirow[t]{3}{*}{0.026} & \multirow[t]{3}{*}{0.029} & \multirow[t]{3}{*}{0.441} \\
\hline & FMF A-F & $6.42 \pm 4.54$ & & & & $6.56 \pm 4.14$ & & & \\
\hline & Control & $10.87 \pm 6.53$ & & & & $12.63 \pm 6.44$ & & & \\
\hline \multirow[t]{3}{*}{2000} & FMF A & $5.29 \pm 4.23$ & \multirow[t]{3}{*}{0.006} & \multirow[t]{3}{*}{0.005} & \multirow[t]{3}{*}{0.634} & $6.17 \pm 3.75$ & \multirow[t]{3}{*}{0.039} & \multirow[t]{3}{*}{0.042} & \multirow[t]{3}{*}{0.507} \\
\hline & FMF A-F & $5.06 \pm 4.11$ & & & & $6.78 \pm 3.94$ & & & \\
\hline & Control & $15.74 \pm 6.73$ & & & & $14.16 \pm 6.36$ & & & \\
\hline \multirow[t]{3}{*}{2800} & FMF A & $9.58 \pm 5.12$ & \multirow[t]{3}{*}{0.003} & \multirow[t]{3}{*}{0.004} & \multirow[t]{3}{*}{0.673} & $10.34 \pm 5.01$ & \multirow[t]{3}{*}{0.008} & \multirow[t]{3}{*}{0.007} & \multirow[t]{3}{*}{0.652} \\
\hline & FMF A-F & $9.78 \pm 5.23$ & & & & $10.12 \pm 4.78$ & & & \\
\hline & Control & $23.18 \pm 6.23$ & & & & $22.38 \pm 5.45$ & & & \\
\hline \multirow[t]{3}{*}{4000} & FMF A & $12.17 \pm 6.27$ & \multirow[t]{3}{*}{0.005} & 0.003 & 0.622 & $11.88 \pm 5.48$ & 0.003 & 0.002 & 0.776 \\
\hline & FMF A-F & $11.94 \pm 6.23$ & & & & $11.65 \pm 5.41$ & & & \\
\hline & Control & $21.37 \pm 7.35$ & & & & $23.37 \pm 7.72$ & & & \\
\hline
\end{tabular}

DPOAE - distortion product otoacoustic emissions, FMF A - familial Mediterranean fever attack period, FMF A-F - familial Mediterranean fever attack-free period, SD - standard deviation

TABLE 3. The AABR values of patients in attack period and attack-free period

\begin{tabular}{|c|c|c|c|}
\hline $\begin{array}{l}\text { ABR variables } \\
\text { (wave } \\
\text { or inter-wave) }\end{array}$ & Groups & $\begin{array}{l}\text { Latencies } \\
\text { mean } \pm S D\end{array}$ & $p$ values \\
\hline \multirow[t]{2}{*}{ I (ms) } & FMF A & $1.59 \pm 0.11$ & \multirow[t]{2}{*}{0.524} \\
\hline & FMF A-F & $1.57 \pm 0.12$ & \\
\hline \multirow[t]{2}{*}{ III (ms) } & FMF A & $3.75 \pm 0.17$ & \multirow[t]{2}{*}{0.545} \\
\hline & FMF A-F & $3.77 \pm 0.11$ & \\
\hline \multirow[t]{2}{*}{$\mathrm{V}$ (ms) } & FMF A & $5.56 \pm 0.15$ & \multirow[t]{2}{*}{0.251} \\
\hline & FMF A-F & $5.39 \pm 0.18$ & \\
\hline \multirow[t]{2}{*}{ I-III (ms) } & FMF A & $2.16 \pm 0.14$ & \multirow[t]{2}{*}{0.397} \\
\hline & FMF A-F & $2.21 \pm 0.11$ & \\
\hline \multirow[t]{2}{*}{ III-V (ms) } & FMF A & $1.81 \pm 0.16$ & \multirow[t]{2}{*}{0.159} \\
\hline & FMF A-F & $1.62 \pm 0.15$ & \\
\hline \multirow[t]{2}{*}{ I-V (ms) } & FMF A & $3.97 \pm 0.13$ & \multirow[t]{2}{*}{0.554} \\
\hline & FMF A-F & $4.03 \pm 0.16$ & \\
\hline
\end{tabular}

$A B R$ - auditory brainstem response, $F M F a$ - familial Mediterranean fever attack period, FMFA- $F$ familial Mediterranean fever attack-free period, SD - standard deviation

tionship between hearing and FMF disease [13], and most of them report contradicting results.

One of the first studies performed at paediatric age was by Koybasi et al. [12], which showed that FMF disease affects cochlear function. In particular, the authors found increased hearing thresholds, including high frequencies in audiometric evaluation, and showed decreased distortion products in the otoacoustic emission evaluation for FMF children when compared to a healthy control cohort. Our findings agree with those results. In this study, we found that the hearing levels of FMF group were significantly higher than the control group at all frequencies tested on the left and at 1000, 4000 , and $8000 \mathrm{~Hz}$ on the right. These findings were supported by the decreased distortion products demonstrated by DPOAE testing in children with FMF when compared to controls.

In contrast with our findings, Uysal et al. [19] found no difference between FMF patients and controls by using Transient Evoked Otoacoustic Emissions (TEOAEs). Moreover, Polat et al. [20] and Cevik et al. [6] were unable to show any significant difference according to the distinct hearing thresholds.

Recently, Keskindemirci et al. [15] compared cochlear functions according to a severity score system. As a result, no significant differences were shown between the FMF group and healthy controls.

Although several studies have investigated cochlear functions in FMF patients, none have taken the periodicity of the attacks into account when the auditory findings have been evaluated. Our study is the first to employ this context. For this reason, we have submitted FMF patients, who were in an attack period, to audiometric evaluation, repeating the tests when they were in an attack-free period. As a result, we found that the hearing thresholds in the attack period compared to the attack-free period 
were increased only at certain frequencies $(250,1000$, and $8000 \mathrm{~Hz}$ and pure tone average on the left and $1000 \mathrm{~Hz}$ and pure tone average on the right), but this was not supported by the DPOAE and ABR tests. This may suggest that hearing impairment in FMF is due to a chronic autoinflammation process, which may, in turn, be due to a substantial amount of subclinical inflammation that persists between attacks [15].

Many pro-inflammatory cytokine secretions are increased even in the period without attacks [21]. Several experimental studies showed that several cytokines such as TNF- $\alpha$, IL- $1 b$, and IL- 6 , besides playing an important role in allergic disease [22], also have a critical role in damaged cochlea. The mechanism and function of these cytokines are still obscure. However, it is believed that the presence of these inflammatory cytokines in cochlear fluid together with monocytes and macrophages can cause cochlear damage $[23,24]$. FMF patients are exposed to intensive cytokine secretion and inflammation both during an attack and in the attack-free period, inducing in this way hearing loss [21], but further studies are required on this subject.

One limitation of the present study is that the relationship between hearing loss and the treatment was not evaluated because all FMF patients were using colchicine. There are studies showing a possible anti-inflammatory effect on the inner ear, while it also has an ototoxic effect [21]. However, the effect of colchicine treatment on the cochlea has not been clearly shown, and there is no study in the literature regarding the effect of oral colchicine preparations on the inner ear or the relationship between the dose and usage duration of oral colchicine and the audiometric evaluations. Our study did not evaluate the age at the onset of disease, constituting a possible limitation that could affect our audiometric results as reported in literature [25]. A correlation analysis between hearing results, age at the onset of disease, and colchicine usage time with different variables and longer study period would be more appropriate to address this issue.

\section{CONCLUSIONS}

In conclusion, our results demonstrated that FMF disease may cause hearing loss in children with FMF. Regarding these results, objective acute impairment in hearing in the attack period was not demonstrated, which may suggest that hearing impairment in FMF is due to a chronic autoinflammation process.

These findings also suggest that regular follow-up of auditory function in FMF children who are unable to express hearing loss may be helpful in determining possible hearing loss in the early stages.

\section{DISCLOSURE}

The authors declare no conflict of interest.

\section{REFERENCES}

1. Shohat M, Halpern GJ. Familial Mediterranean fever - a review. Genet Med 2011; 13: 487-488.

2. Vitale A, Rigante D, Lucherini OM, et al. The diagnostic evaluation of patients with a suspected hereditary periodic fever syndrome: experience from a referral center in Italy. Intern Emerg Med 2017; 12: 605-611.

3. Bonfrate L, Scaccianoce G, Palasciano G, et al. A novel cluster of patients with familial Mediterranean fever in Southern Italy. Eur J Clin Invest 2017; 47: 622-629.

4. La Regina M, Nucera G, Diaco M, et al. Familial Mediterranean fever is no longer a rare disease in Italy. Eur J Hum Genet 2003; 11: $50-56$.

5. Ben-Chetrit E, Touitou I. Familial mediterranean Fever in the world. Arthritis Rheum 2009; 61: 1447-1453.

6. Cevik C, Silfeler I, Arica V, et al. Determination of hearing levels in patients with Familial Mediterranean Fever. Int J Pediatr Otorhinolaryngol 2013; 77: 2040-2043.

7. International FMF Consortium. Ancient missense mutations in a new member of the RoRet Gene family are likely to cause Familial Mediterranean Fever. Cell 1997; 90: 797-807.

8. French FMF Consortium. A candidate gene for Familial mediterranean fever. Nat Genet 1997; 17: 25-31.

9. Shinkai K, Kilcline C, Connolly MK, et al. The pyrin family of fever genes: unmasking genetic determinants of autoinflammatory disease. Arch Dermatol 2005; 141: 242-247.

10. Turkish FMF Study Group. Familial Mediterranean fever (FMF) in Turkey: results of a nationwide multicenter study. Medicine 2005; 84: 1-11.

11. Nir-Paz R, Ben-Chetrit E, Pikarsky E, et al. Unusual presentation of familial Mediterranean fever: role of genetic diagnosis. Ann Rheum Dis 2000; 59: 836-838.

12. Koybasi S, Atasoy HI, Bicer YO, et al. Cochlear involvement in Familial Mediterranean Fever: a new feature of an old disease. Int J Pediatr Otorhinolaryngol 2012; 76: 244-247.

13. Lordoglu B, Acar B, Yazilitas F, et al. Evaluation of cochlear functions in children with Familial Mediterranean Fever. Int J Pediatr Otorhinolaryngol 2016; 87: 139-142.

14. Bucak A, Ulu S, Bukulmez A, et al. Inner Ear Involvement in Children with Familial Mediterranean Fever. J Int Adv Otol 2014; 10 : 124-127.

15. Keskindemirci G, Ayaz NA, Batioglu-Karaaltin A, et al. Cochlear functions in children with familial Mediterranean fever: any role of the severity of the disease? Int J Pediatr Otorhinolaryngol 2015; 79: 1566-1570.

16. Pras M. What is familial Mediterranean fever. Familial Mediterranean Fever; II International Conference, 3-7 May 2000, Antalya, Turkey.

17. Fodale V, Pratico C, Santamaria LB. Coadministration of propofol and midazolam decreases bispectral index value as a result of synergic muscle relaxant action on the motor system. Anesthesiology 2004; 101: 799.

18. Gillberg C, Rosenhall U, Johansson E. Auditory brainstem responses in childhood psychosis. J Autism Dev Disord 1983; 13: 181-195.

19. Uysal İÖ, Gürbüzler L, Kaya A, et al. Evaluation of cochlear function using transient evoked otoacoustic emission in children with Familial Mediterranean Fever. Int J Pediatr Otorhinolaryngol 2012; 76: 379-381.

20. Polat K, Uysal İÖ, Şenel S, et al. Evaluation of hearing in patients with familal Mediterranean fever. Eur Arch Otorhinolaryngol 2013; 270: 2871-2874.

21. Eryilmaz MA, Yucel A, Cure E, et al. The evaluation of cochlear functions in Familial Mediterranean Fever. Eur Arch Otorhinolaryngol 2016; 273: 4119-4126. 
22. La Mantia I, Andaloro C. Demographics and clinical features predictive of allergic versus non-allergic rhinitis in children aged 6-18 years: A single-center experience of 1535 patients. Int J Pediatr Otorhinolaryngol 2017; 98: 103-109.

23. Pathak S, Goldofsky E, Vivas EX, et al. IL-1b is overexpressed and aberrantly regulated in corticosteroid nonresponders with autoimmune inner ear disease. J Immunol 2011; 186: 1870-1879.

24. Adams JC. Clinical implications of inflammatory cytokins in the cochlea: a technical note. Otol Neurotol 2008; 23: 1043-1049.

25. Yalçinkaya F, Özçakar ZB, Tanyıldız M, et al. Paediatric rheumatology Familial Mediterranean fever in small children in Turkey. Clin Exp Rheumatol 2011; 29: S87-S90. 